\title{
Rules and more rules: The effects of multiple tasks, extensive training, and aging on task-switching performance
}

\author{
Norbou G. Buchler, William J. Hoyer, And John Cerella \\ Syracuse University, Syracuse, New York
}

\begin{abstract}
Task-switching performance was assessed in young and older adults as a function of the number of task sets to be actively maintained in memory (varied from 1 to 4 ) over the course of extended training ( 5 days). Each of the four tasks required the execution of a simple computational algorithm, which was instantaneously cued by the color of the two-digit stimulus. Tasks were presented in pure (task set size 1) and mixed blocks (task set sizes 2, 3, 4), and the task sequence was unpredictable. By considering task switching beyond two tasks, we found evidence for a cognitive control system that is not overwhelmed by task set size load manipulations. Extended training eliminated age effects in task-switching performance, even when the participants had to manage the execution of up to four tasks. The results are discussed in terms of current theories of cognitive control, including task set inertia and production system postulates.
\end{abstract}

Despite a person's best intentions to seamlessly manage multiple tasks, it has long been known that there is a delay, or a "switch cost," associated with switching from one task to another. In Jersild's (1927) early experiments on "switch loss," performance was slowed by more than $400 \mathrm{msec}$ per item when participants were required to switch between adding 3 to a two-digit number and subtracting 3 from it, in comparison with a pure (unmixed) condition. Results of numerous, more recent studies show similar findings using a wide variety of tasks and procedures (see, e.g., Allport, Styles, \& Hsieh, 1994; Koch, Prinz, \& Allport, 2005; Mayr \& Kliegl, 2000; for a review, see Pashler, 2000), and a variety of explanations have been advanced to account for the observed patterns of switch costs (e.g., Rogers \& Monsell, 1995; Sohn \& Anderson, 2001; Yeung \& Monsell, 2003). It is also well established that there is an age-related deficit in at least some aspects of task switching (e.g., Hahn, Andersen, \& Kramer, 2004; Kray, Li, \& Lindenberger, 2002; Mayr, 2001; Wecker, Kramer, Hallam, \& Delis, 2005; for a meta-analysis, see Verhaeghen \& Cerella, 2002). Given the prevalence and persistency of task-switch costs as well as age-related deficits, managing multiple tasks can be described as being taxing on the cognitive system.

Yet, there have been few attempts to push the limits of multitasking performance beyond alternating between two tasks. More than two task sets have been used in only a few experiments examining the effects of task set size on switch costs (Altmann, 2002 [Experiment 3]; Kramer, Hahn, \& Gopher, 1999 [Experiments 2 \& 3]; Kray et al., 2002; Monsell, Sumner, \& Waters, 2003 [Experiment 2];
Rogers \& Monsell, 1995 [Experiment 6]; Ruthruff, Remington, \& Johnston, 2001 [Experiment 3]), presumably because it is hard to establish the equivalence of processing demands for multiple tasks.

Our investigation is focused on a detailed examination of task-switching performance on multiple tasks. The number of tasks to be held active was systematically varied from one to four. In order to render an equitable task set size manipulation, we carried out extensive preliminary testing in order to identify a set of four tasks that were equivalent in terms of computational complexity (as defined by a parametric analysis of their distribution of response latencies). The tasks used in the present experiment involved novel arithmetic-like operations for solving problems. The four tasks were: addition, subtraction, smallest digit plus one, and largest digit minus one. The color of the stimulus - a pair of digits - signaled which task operator to use.

Another focus of our study was to examine the influence of aging as well as possible practice-related decreases in the costs associated with managing multiple tasks over the course of training. Several advantages were conferred by designing our experiment as a training study. First, we were able to examine whether task-switch costs persist across training, as well as the degree to which task-switch costs can be "practiced away." Second, after extensive training, participants achieved a stable baseline of performance when the learning curve flattened out. This method offers both a meaningful benchmark of performance and also facilitates comparison between the two age groups of young and older adults.

N. G. Buchler, norbou.buchler@duke.edu 
The locus of age-related neurodegeneration in the frontal lobe has implicated cognitive control processes - such as those involved in task switching - as a source of pronounced age-related impairment (West, 1996). Indeed, age-related task-switch costs are a prevalent finding in the research literature (Verhaeghen \& Cerella, 2002). However, there is some promising evidence that age-related switch costs can be "practiced away." Although only two aging studies have examined practice-related effects on task-switch costs, the results have been surprising. Across two sessions of practice, Cepeda, Kramer, and Gonzales de Sather (2001) found a reduction in task-switch costs at all ages of the lifespan. Remarkably, Kramer et al. (1999, Experiment 1) found that across four sessions of practice, age-related differences in task-switch costs between young and older adults could be completely eliminated. Early in practice, there were large age-related differences in switch costs. However, after three sessions of practice, older adult task-switch costs were found to be equivalent to those of young adults.

With a mental load, however, Kramer et al. (1999, Experiment 3) also found evidence that older adults were less able to capitalize on training when required to keep track of when they were to switch (i.e., every 5th trial). Unfortunately, Kramer et al.'s study did not examine older adult performance under a condition of increased mental load beyond two sessions, so it is unknown whether older adults can achieve similar task-switching performance as can young adults under mental load conditions. The age-related focus of our study examined the confluence of these two factors: increased mental load (i.e., multiple tasks) and extended training (five sessions). Given the interaction of age and mental load on task-switching performance (Kramer et al., 1999), we hypothesized that older adult switch costs would increase with the number of tasks in the set, more so than they would in young adults. Furthermore, with the participants undergoing extensive training, we hypothesized that age-related differences in a task-switch cost would be reduced or eliminated when older adults were required to switch between two tasks. However, when older adults are required to switch between three and four tasks, we predicted that we might find a limit to practice-related improvements, or that older adults would require more training.

\section{Task Switching}

The task-switching literature has identified a top-down preparatory mechanism that can increase the accessibility of a task set. With foreknowledge of an upcoming task switch, the costs to performance decrease considerably (Rogers \& Monsell, 1995; Sohn \& Anderson, 2001). In an examination of predictable and unpredictable task switching, Monsell et al. (2003) suggested that task readiness can be strategically modulated by expectation or awareness of the probability of an upcoming task switch. In predictable task switching - in which a visual cue marked the position in the run - one trial was sufficient to recover asymptotic performance in the task, suggesting an all-or-none control setting. When task switching was unpredictable, performance improved over runs of two or three trials. However, it did not reach the predictable switching asymptote, suggesting that the control setting was adjusted flexibly and incrementally.

In an unpredictable task-switching environment, it is possible that the cognitive system is broadly configured to maintain a number of task sets in a state of heightened accessibility. For instance, Los (1999) argued that switch costs reflect differences in mental load:

Participants must maintain readiness for either level of the variable in mixing blocks, but only for one level in pure blocks. As a result, less capacity is available for processes called on in mixing blocks than for these processes in pure blocks, thus reducing processing efficiency. The key feature of this conception of mental load is its static character, because it assumes that the participant continually maintains preparedness for all possible events that may occur in a given block of trials. (p. 4)

We hypothesized that if the cognitive system is broadly configured to maintain preparedness for all possible tasks, then increasing the number of tasks should systematically prolong the switch cost. Furthermore, we hypothesized that if preparedness is maintained for all tasks, then, as a general effect, even the speed in responding when repeating a task should be systematically prolonged when task set size is increased.

There is considerable debate about the precise mechanism responsible for the switch cost, although an emerging consensus is that both top-down preparatory and bottom-up stimulus-driven processes are involved (Allport \& Wylie, 1999, 2000; Kieras, Meyer, Ballas, \& Lauber, 2000; Meiran, 2000; Monsell, Yeung, \& Azuma, 2000; Ruthruff et al., 2001; Sohn \& Anderson, 2001; Yeung \& Monsell, 2003). A number of top-down executive preparatory processes have been proposed, such as task-set reconfiguration (Mayr \& Keele, 2000; Monsell, 2003), the intermittent failure of a preparatory process (De Jong, 2000; also with passive decay, see Sohn \& Anderson, 2001), and goal shifting (Rubinstein, Meyer, \& Evans, 2001). There are clear limits to the preparatory advantage in task switching. Switch costs persist, even with foreknowledge, and such diminished costs - termed residual switch costs - do not disappear, even after a preparatory interval of 5,000 msec (Rogers \& Monsell, 1995; Sohn \& Anderson, 2001). In other words, the cognitive system cannot completely prepare for a switch when given advanced preparation, and it requires the stimulus to be present to complete the task switch; that is, it is a bottom-up, stimulus-driven process.

A number of bottom-up processes have been proposed, such as the idea that the configuration of a previous task contributes persisting interference - termed task set inertia - which has been shown to decay as a function of the response-stimulus interval (Allport et al., 1994; Allport \& Wylie, 1999; Altmann, 2002; Arbuthnott \& Frank, 2000; Mayr, 2002; Mayr \& Keele, 2000; Meuter \& Allport, 1999; Nieuwenhuis \& Monsell, 2002; Wylie $\&$ Allport, 2000). Arguments in favor of top-down or bottom-up components of cognitive control are derived from a number of task-switching functions - such as posi- 
tion in a run (see, e.g., Rogers \& Monsell, 1995) and lag recency - which we will use to describe performance in our examination of unpredictable task-switching performance among up to four tasks.

\section{Task-Switch Costs}

Task-switching performance is typically assessed by specific and general switch costs. General switch costs are defined as a between-blocks measure reflecting the latency difference between a task-switching condition and a nonswitch condition, whereas specific switch costs are defined within a task-switch block as the difference between switch and nonswitch trials. The general switch cost is confounded by the repetition benefit, which is conferred to only a portion of nonswitch trials in the taskswitch block and to all trials in the single task block. For this reason, a number of researchers have used a mixing switch cost, which is a refinement of the general switch cost, since it equates task repetitions in the pure and mixed blocks of trials (Fagot, 1994; Los, 1999; Meiran \& Gotler, 2001). To avoid confusion, one particular approach that we adopted was to represent the data separately for task switches and task repetition. All three types of switch costs - specific, general, and mixing — are readily apparent in a plot of these values.

\section{METHOD}

\section{Participants}

The participants were 15 young adults $(M=18.67$ years, $S D=$ $1.54)$ and 16 older adults $(M=68.88$ years, $S D=4.47)$. Young adults received both course credit and $\$ 15$, and older adults received $\$ 85$ for their participation. Young adults averaged 12.9 years of education $(S D=1.3)$, and older adults averaged 15.7 years of education $(S D=2.6)$; the difference was significant $[t(28)=3.92]$. Young adults had forward and backward digit spans (Wechsler, $1981)$ of $10.6(S D=1.7)$ and $6.6(S D=2.1)$, respectively. Older adults had forward and backward digit spans of $9.9(S D=2.3)$ and $7.6(S D=1.8)$, respectively. These differences were not significant $[t(28)=0.95$, and $t(28)=-1.44]$. Digit symbol substitution scores (Wechsler, 1981) were better for young adults $(61.3 ; S D=10.8)$ than for older adults $(44.4 ; S D=10.0)[t(28)=4.42]$.

\section{Procedures}

The experiment consisted of a preliminary session along with either four or five subsequent experimental sessions administered on consecutive days. All of the 15 young adult participants completed four experimental sessions, and 8 young adults completed an additional fifth session. Attrition on Day 5 was due to the observance of a religious holiday. All 16 older adults completed five sessions of testing.

In the preliminary session, participants practiced both entering digits using the numeric keypad and the four task operations used in the experiment. Digit copy practice consisted of 70 trials in which the participant made a response on the number keypad to match a digit presented at the center of the computer screen. Task operations were practiced in four "unmixed" (i.e., "pure") blocks of 70 trialsone block for each task.

Experimental sessions involved initial blocks of digit copy trials and pure trial blocks of each task (just as in the preliminary session), along with subsequent blocks containing mixes of all possible combinations of two, three, and four tasks. That is, an experimental sessions consisted of 16 blocks: 1 block of digit copy trials, 4 pure blocks (a block of 70 trials for each task), 6 blocks of all combinations of any two tasks, 4 blocks of all combinations of any three tasks, and 1 block of all four tasks. Participants solved the same number of problems (144 problems, 36 of each task) at each set size while stepping through 6 "set size 2" blocks, 4 "set size 3" blocks, and 1 "set size 4" block. This was accomplished by adjusting the number of trials in each mixed block to equate the total numbers of problems for each task within each set size. In order to motivate their performance, we provided participants with summary-statistic feedback (mean, median, percent correct) at the end of each block.

The stimuli were two-digit numbers, and responses consisted of keying a single digit on the numeric keypad. Stimuli were randomly selected from the set of all possible two-digit stimuli for a task without replacement; thus, stimuli were never repeated within a block. The color of the two-digit stimulus was used to cue the task operation to be applied in calculating the solution. The four tasks (and their color cues) were addition (green), subtraction (red), smallest digit plus one (yellow), and largest digit minus one (blue). The addition task required reporting the sum of two digits (e.g., $34=7$ ). If the sum was greater than 9, then only the units digit was reported (e.g., $78=5$ ). The subtraction task required reporting the value of the absolute difference between two digits (e.g., $48=4$ ). The smallest digit plus one task required reporting the digit obtained by adding 1 to the smaller of two digits (e.g., $38=4$ ). The largest digit minus one task required reporting the digit obtained by subtracting 1 from the larger of two digits (e.g., $38=7$ ). The addition and subtraction tasks had 72 problem instances, and the smallest digit plus one and the largest digit minus one tasks had 82 problem instances. These tasks were selected on the basis of pilot testing a larger number of candidate tasks. The four that were chosen had similar median response latencies and similar ex-Gaussian distributions of response times (RTs), as assessed in pure blocks.

A trial consisted of the presentation of a fixation cue (- -) for $1 \mathrm{sec}$, followed by the presentation of the stimulus until the participant made a response, followed by a blank screen for $700 \mathrm{msec}$. Error responses were immediately followed by the presentation of an error message for $300 \mathrm{msec}$ together with an auditory signal.

The two-digit stimuli were presented in the center of the computer screen and subtended $2.29^{\circ}\left(x\right.$-axis) and $1.60^{\circ}(y$-axis) of visual angle at a viewing distance of $50 \mathrm{~cm}$. All of the stimuli were presented as colored digits on a gray background. In the digit copy task, colors were randomly assigned to single digits, and the participants were instructed to ignore the color of the digits. This requirement allowed us to check that digit copy latencies did not differ by color.

\section{Task-Switch Frequencies}

The trial sequence for mixed blocks was carefully controlled. To avoid confounding larger set sizes with more switches between tasks, the probability of switching was fixed at $66 \%$. This, in turn, fixed the probability of repeating a task at $33 \%$. At the same time, the number of problems within the set size series of blocks was equated for each task. These constraints were satisfied by constructing trial sequences from four-trial schemas. There were six schemas for set size 2 (given tasks $\mathrm{A}$ and $\mathrm{B}$ ): $\mathrm{AABA}, \mathrm{ABBA}, \mathrm{ABAA}, \mathrm{BBAB}, \mathrm{BAAB}$, and $\mathrm{BABB}$. There were nine schemas for set size 3 (given tasks $A, B$, and $C$ ): AABA, ABBA, ACAA, BBAB, BCCB, BCAA, CCAC, CBBC, and CBCC. There were 12 schemas for set size 4: AABD, ACCD, ACBB, BBCA, BDDC, BDAA, CCAD, CBBA, CADD, DDCB, DAAB, and DBCC. ${ }^{1}$ A complete trial sequence for a mixed block was assembled by concatenating randomly selected schema from the set appropriate for the block until the required number of trials was met. In this way, the number of problems for each task was equalized, and the types of switches between tasks (i.e., AC, BD, etc.) were balanced.

\section{RESULTS AND DISCUSSION}

The first 20 trials of each block were considered a reconfiguration period and were discarded as part of the experimental design. Trials with response latencies of less than $250 \mathrm{msec}$ and longer than $5,000 \mathrm{msec}$ were not in- 
cluded in the RT data analysis. Using this criterion, $1.08 \%$ of trials were discarded from the data taken from young adults, and $1.51 \%$ of trials were discarded from the data from older adults.

\section{Defining Trained Performance}

As expected, RTs improved with practice across consecutive sessions (Newell \& Rosenbloom, 1981). Because practice effects contribute unwanted variability to the analysis of set size, we sought to determine the point in training at which RTs stopped improving. We performed a trend analysis on the sessions factor and tested for the presence of a significant linear or quadratic trend, separately on the data for each set size and age group. The first analysis used all five (or four) sessions. We then dropped the first session and analyzed the remaining four (or three) sessions. Finally, we dropped the second session and analyzed the last three sessions. Table 1 shows the results of these tests. With the early sessions included, the linear or quadratic trend was always significant. Over the last three sessions, however, no linear or quadratic trend was significant. Performance was flat and thus at asymptote. For the subsequent analyses, data were combined over the last three sessions, which constituted a stable baseline of trained performance.

\section{Shape of the Task-Switching Load Function}

Mean median RT set size functions for young and older adults for task-repetition trials and task-switch trials are shown in Figure $1 .^{2}$ The RTs for the digit copy task are also presented. First, we performed a set of ANOVAs that

Table 1

Summary of Polynomial Regression Trend Analysis on the Learning Curves of Young and Older Adults Significant Trends

\begin{tabular}{|c|c|c|c|}
\hline \multicolumn{4}{|c|}{ Significant Trends } \\
\hline & \multicolumn{2}{|c|}{ Young Adults $(n=15)$} & \\
\hline Days $1,2,3$, & & & \\
\hline Set size 1 & Intercept ${ }^{* * *}$ & Linear* & \\
\hline Set size 2 & Intercept ${ }^{* * *}$ & Linear* & \\
\hline Set size 3 & Intercept ${ }^{* * *}$ & & \\
\hline Set size 4 & Intercept $^{* * *}$ & Linear* & \\
\hline \multicolumn{4}{|l|}{ Days 2, 3, 4} \\
\hline Set size 1 & \multicolumn{2}{|l|}{ Intercept ${ }^{* * *}$} & \\
\hline Set size 2 & \multicolumn{2}{|l|}{ Intercept ${ }^{* * * *}$} & \\
\hline Set size 3 & \multicolumn{2}{|l|}{ Intercept ${ }^{* * *}$} & \\
\hline Set size 4 & \multicolumn{2}{|l|}{ Intercept ${ }^{* * * *}$} & \\
\hline & \multicolumn{2}{|c|}{ Older Adults $(n=16)$} & \\
\hline \multicolumn{4}{|c|}{ Days $1,2,3,4,5$} \\
\hline Set size 1 & Intercept ${ }^{* * *}$ & Linear* & \\
\hline Set size 2 & Intercept ${ }^{* * *}$ & Linear* & Quadratic* \\
\hline Set size 3 & Intercept ${ }^{* * *}$ & Linear** & Quadratic* \\
\hline Set size 4 & Intercept ${ }^{* * *}$ & Linear*** & \\
\hline \multicolumn{4}{|c|}{ Days $2,3,4,5$} \\
\hline Set size 1 & Intercept ${ }^{* * *}$ & & \\
\hline Set size 2 & Intercept ${ }^{* * *}$ & Linear** & \\
\hline Set size 3 & Intercept ${ }^{* * * *}$ & Linear** & \\
\hline Set size 4 & Intercept ${ }^{* * *}$ & Linear* & \\
\hline \multicolumn{4}{|l|}{ Days $3,4,5$} \\
\hline Set size 1 & Intercept ${ }^{* * *}$ & & \\
\hline Set size 2 & Intercept ${ }^{* * *}$ & & \\
\hline Set size 3 & Intercept ${ }^{* * *}$ & & \\
\hline Set size 4 & Intercept ${ }^{* * *}$ & & \\
\hline
\end{tabular}

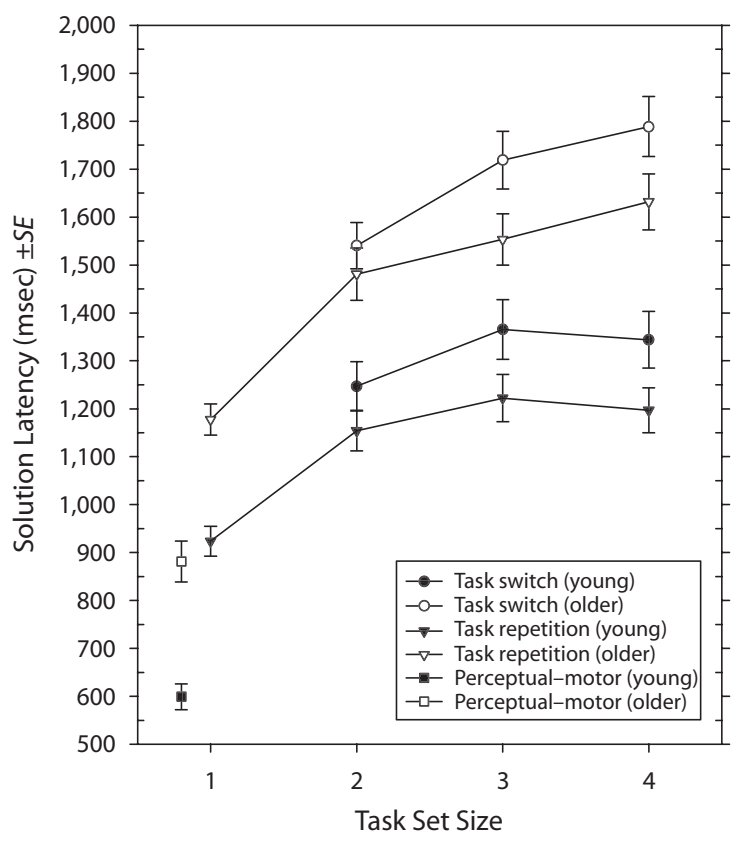

Figure 1. Young (filled symbols) and older (open symbols) adult asymptotic mean median solution latency for task-switch and task-repetition trials as a function of set size, collapsed across tasks (addition, subtraction, smallest +1 , largest -1 ). The leftmost points are the mean median perceptual-motor response latencies for the young and older adults on the digit copy task.

compared switch and nonswitch (repetition) trials, on the basis of a two-level switch factor spanning the two trial types. These data are available over set sizes 2, 3, and 4 only, and they form the basis for calculating specific switch costs. These data were submitted to a 2 (age) $\times 3$ $($ set size $) \times 4$ (task) $\times 2$ (switch) ANOVA. There were significant main effects of age $\left[F(1,696)=127.62, M S_{\mathrm{e}}=\right.$ $24,613,245, p<.0001]$, set size $\left[F(2,696)=6.57, M S_{\mathrm{e}}=\right.$ $1,267,431, p<.001]$, and switch trials $[F(1,696)=15.65$, $\left.M S_{\mathrm{e}}=3,018,678, p<.0001\right]$. Performance did not vary by task $\left[F(3,696)=0.54, M S_{\mathrm{e}}=104,899\right.$, n.s. $]$, so the data in Figure 1 are collapsed across tasks. There were no interactions, including age $\times$ set size $[F(2,696)=1.46$, $M S_{\mathrm{e}}=282,474$, n.s. $]$, set size $\times$ switch $[F(2,696)=$ $0.64, M S_{\mathrm{e}}=123,116$, n.s.], and age $\times$ set size $\times$ switch $\left[F(2,696)=0.07, M S_{\mathrm{e}}=13,277\right.$, n.s. $]$. In this analysis the specific switch cost is captured by the switch factor. Specific switch costs were incurred for the number-reduction tasks; they did not increase with $n$, and they were independent of age.

Next, we analyzed just task-repetition trials, which are a useful baseline of performance common to all experimental factors - set size, task, age — and include the single task baselines. Task-repetition trials are the basis for calculating switch costs due to mixing. The task-repetition data were analyzed first by means of a 2 (age) $\times 4$ (set size) $\times$ 4 (task) ANOVA. There were significant $(p<.0001)$ main effects of age $\left[F(1,464)=96.66, M S_{\mathrm{e}}=14,037,881\right]$, and set size $\left[F(3,464)=23.61, M S_{\mathrm{e}}=3,428,685\right]$. There was 
no main effect of task $\left[F(3,464)=0.13, M S_{\mathrm{t}}=19,295\right.$, n.s.]. There were no interactions, including age $\times$ set size $\left[F(3,464)=1.18, M S_{\mathrm{e}}=171,705\right.$, n.s. $]$.

Continuing with the repetition data, the difference between the baseline condition (set size 1) and repetition in the multiple task conditions (set sizes 2, 3, and 4) were assessed by means of a planned contrast. The difference captures the mixing cost (see Fagot, 1994; Los, 1999; Meiran \& Gotler, 2001). The mixing cost was examined in an ANOVA involving age and set size $(2,3,4)$. Although there were general age-related differences $\left[F(1,366)=75.11, M S_{\mathrm{e}}=\right.$ $12,326,725, p<.0005]$, there was neither an effect of set size $\left[F(2,366)=1.88, M S_{\mathrm{e}}=308,573\right.$, n.s. $]$, nor an age $\times$ set size interaction $\left[F(2,366)=0.71, M S_{\mathrm{e}}=115,841\right.$, n.s. $]$. Thus, the switch cost for task-repetition trials (i.e., mixing cost) - the difference between task-repetition trials in the single task baseline condition $(n=1)$ and in the multiple task conditions $(n>1)$-remained constant as $n$ increased beyond 2 to 3 to 4 . In sum, mixing costs were incurred for the number-reduction tasks, but these costs did not increase further beyond the initial set size 2 . They were also independent of age, as indicated by the lack of an age $\times$ set size interaction. The mixing cost for young and older adults was of comparable magnitude.

\section{Accuracy}

The accuracy data are displayed in Figure 2 as a function of age and task set size for task-repetition and taskswitch trial types. Overall, both young $(M=97.0 \%)$ and older adults $(M=98.4 \%)$ maintained high levels of accuracy that were largely invariant (1\%-2\% drop) across the set size manipulation. Accuracy was examined under task-switching conditions with a 2 (age) $\times 2$ (switch) $\times$ 3 (set size) $\times 4$ (task) ANOVA and revealed a main effect of age $\left[F(1,696)=35.77, M S_{\mathrm{e}}=.034, p<.0001\right]$, but no differences due to set size $\left[F(2,696)=0.91, M S_{\mathrm{e}}=.0009\right.$, n.s. $]$, task $\left[F(3,696)=1.13, M S_{\mathrm{e}}=.0011\right.$, n.s. $]$, or switch $\left[F(1,696)=0.50, M S_{\mathrm{e}}=.0005\right.$, n.s. $]$. There was a significant age $\times$ switch interaction $\left[F(1,696)=4.06, M S_{\mathrm{e}}=\right.$ $.0038, p=.044]$. No other interactions were significant, including that of age $\times$ set size $\left[F(3,696)=0.38, M S_{\mathrm{e}}=\right.$ .0004 , n.s.]. Thus, older participants were slightly more accurate than young, and slightly more so for task-switch trials. Age "reversals" of this sort have been reported in other studies of mental arithmetic (Geary, Frensch, \& Wiley, 1993; Salthouse \& Coon, 1994). The main effects of age, switching, and set size that were reported earlier in the response latency data are not due to a speed-accuracy trade-off, since high levels of accuracy (above 96\% in all cases) were uniformly maintained.

\section{Effects of Color Cues}

As a check on the distinctiveness of the cue colors (of particular concern with older participants, see National Research Council, 1990), the single digits presented during digit entry practice were assigned one of the four colors on a random basis. When digit entry times were partitioned by color, there was no effect of color for either young adults $\left[F(3,56)=0.03, M S_{\mathrm{e}}=426\right.$, n.s. $]$, or older adults $\left[F(3,60)=0.04, M S_{\mathrm{e}}=1,857\right.$, n.s. $]$.

\section{Locus of Age-Related Improvements \\ Due to Practice}

One of the most surprising findings to emerge out of our analyses of specific and mixing switch costs was the lack of any age-related interactions with either set size or the "switch" factor. Our findings are discrepant with a number of studies demonstrating significant-even disproportional-age effects on general switch costs (Kray \& Lindenberger, 2000; for a meta-analysis, see Verhaeghen \& Cerella, 2002). Our results, however, are consistent with previous research demonstrating that

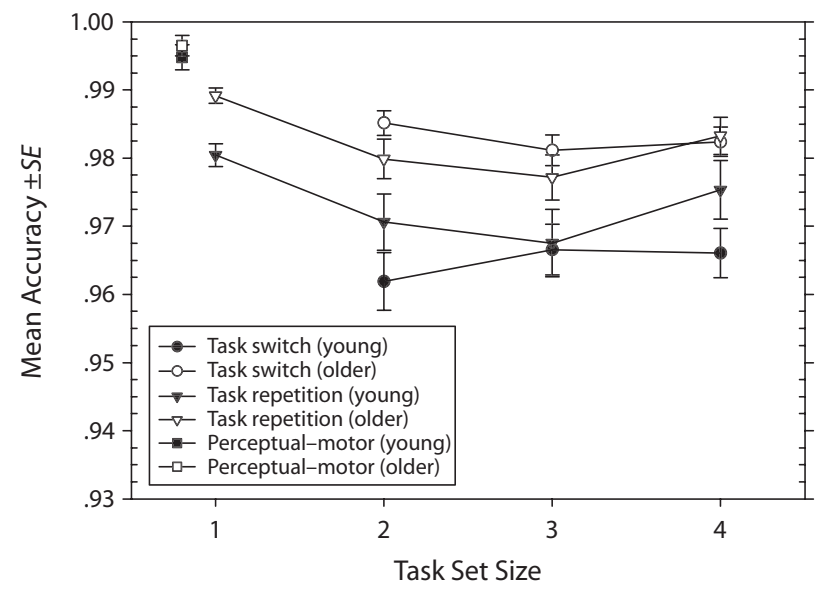

Figure 2. Young (filled symbols) and older (open symbols) adult mean accuracy as a function of set size for task-switch and task-repetition trials. Performance is collapsed across the four tasks: addition, subtraction, smallest +1 , largest -1 . Digit copy task accuracy is shown as the leftmost points. 
practice can diminish (Cepeda et al., 2001) and even eliminate (Kramer et al., 1999) age-related differences in task-switching performance. It is possible, then, that age effects that were present early in training disappeared with practice. We examined the effects of practice on agerelated task-switching performance by applying to the initial Session 1 data the same set of analyses used previously to assess trained performance. The results are tabulated in the leftmost column of Table 2. In the Session 1 data, older adults incurred additional mixing and specific switch costs, especially in response to increases in task set size. When compared with trained performance (second column from left), it is evident that these age effects disappeared with practice.

The elimination of age effects with training suggests that older adults benefit from practice to a greater extent than do young adults. Shown in Figure 3, we examined age-related differences across the daily sessions as a performance ratio, expressing mean median older adult solution latency in proportion to young adult performance. Age ratios are useful for assessing whether age-related differences are either general or specific to a task domain or cognitive process (see Cerella, 1990). Of interest is whether the relative practice-related speedup in older adult performance is general or specific. That is, do all aspects of older adult task performance improve equally, or are practice-related gains conferred specifically to either task-switching, task-repetition, or perceptual-motor processes? As is evident in Figure 3 (panel A), the age ratio remained constant with four sessions of training for both the digit copy task $\left[F(3,60)=0.46, M S_{\mathrm{e}}=0.04\right.$, n.s. $]$ and for task-repetition trials $\left[F(3,1008)=1.93, M S_{\mathrm{e}}=0.25\right.$, n.s.] across task set size. In these cases, older adults benefited from practice to the same degree as did young adults. However, in Figure 3 (panel B), it is also evident that older adult latencies on task-switch trials decreased markedly in relation to young adult performance as a function of training $\left[F(3,756)=11.91, M S_{\mathrm{e}}=1.82, p<.0005\right]$ across task set size. The age ratio was directly compared with a "switch" factor spanning task-switch and task-repetition trials in a 4 (session) $\times 3$ (set size) $\times 2$ (switch) ANOVA. The age ratio declined across practice sessions to a greater extent for switch trials, given by the significant interaction of session $\times$ switch $\left[F(3,1512)=4.23, M S_{\mathrm{e}}=0.64\right.$, $p<.01]$. Thus, older adult performance improved markedly with practice on task-switch trials - much more so than it did for young adults. These results support prior research by Kramer et al. (1999) and also demonstrate that although task switching is an initial source of agerelated differences, it is also the locus of significant practice-related improvement to older adult performance. This positive outcome supports the use of training interventions to eliminate age-related differences in having to switch between tasks. In contrast, our negative outcome is that perceptual-motor processes are also a significant source of age-related differences ( $M=1.52$ times slower); however, this age-related loss of perceptual-motor performance is immutable and cannot be improved with extended training.

\section{Perceptual-Motor Correction}

In trained performance, the absence of any age $\times$ set size interactions indicates that the age effect was an additive one. The size of the age-related differences (338 msec averaged over all the number-reduction conditions) observed in Figure 1 was not too different from the age difference in digit copy times $(282 \mathrm{msec})$. This coincidence raises the possibility that the age-related differences in solving number-reduction problems - both by themselves and in the task-switching conditions-was due to noth-

Table 2

$F$ Values for ANOVAs

\begin{tabular}{|c|c|c|c|c|c|}
\hline \multirow[b]{2}{*}{ Variables } & \multirow[b]{2}{*}{$d f$} & \multicolumn{2}{|c|}{ Raw Data } & \multicolumn{2}{|c|}{$\begin{array}{l}\text { Perceptual-Motor } \\
\text { Adjusted Data }\end{array}$} \\
\hline & & Session 1 & Trained & Session 1 & Trained \\
\hline \multicolumn{6}{|c|}{ Task Switch and Task Repetition } \\
\hline Age & $(1,696)$ & $242.12^{* * *}$ & $127.62^{* * *}$ & $87.63^{* * *}$ & $10.61^{* * *}$ \\
\hline Set size (SS) & $(2,696)$ & $6.91^{* *}$ & $6.57^{* * *}$ & $9.13^{* * *}$ & $10.76^{* * *}$ \\
\hline Switch (Sw) & $(1,696)$ & $19.73^{* * *}$ & $15.65^{* * *}$ & $26.05^{* * *}$ & $25.65^{* * *}$ \\
\hline Age $\times$ SS & $(2,696)$ & $3.42^{*}$ & 1.46 & $4.52^{*}$ & 2.40 \\
\hline Age $\times$ Sw & $(1,696)$ & $7.98^{* *}$ & 0.00 & $10.54^{* *}$ & 0.00 \\
\hline $\mathrm{SS} \times \mathrm{Sw}$ & $(2,696)$ & 1.16 & 0.64 & 1.53 & 1.05 \\
\hline Age $\times \mathrm{SS} \times \mathrm{Sw}$ & $(2,696)$ & 0.26 & 0.07 & 0.34 & 0.11 \\
\hline \multicolumn{6}{|c|}{ Task Repetition Only } \\
\hline Age & $(1,464)$ & $112.60^{* * *}$ & $96.66^{* * *}$ & $15.94^{* * *}$ & $4.54^{*}$ \\
\hline SS & $(3,464)$ & $43.70^{* * *}$ & $23.61^{* * *}$ & $60.33^{* * *}$ & $42.05^{* * *}$ \\
\hline Task & $(3,464)$ & 0.18 & 0.13 & 0.24 & 0.24 \\
\hline Age $\times$ SS & $(3,464)$ & $4.12^{* *}$ & 1.18 & $5.72^{* * *}$ & 2.11 \\
\hline \multicolumn{6}{|c|}{ Contrast Statements: Young Versus Old } \\
\hline SS 1 & $(1,124)$ & $6.68^{* * *}$ & $13.73^{* * *}$ & 1.35 & 0.30 \\
\hline SS 2 & $(1,124)$ & $23.63^{* * *}$ & $22.79^{* * *}$ & 2.17 & 0.77 \\
\hline SS 3 & $(1,124)$ & $44.40^{* * *}$ & $23.36^{* * *}$ & $12.92^{* * *}$ & 0.91 \\
\hline SS 4 & $(1,124)$ & $50.05^{* * *}$ & $40.32^{* * *}$ & $16.63^{* * *}$ & $8.88^{* *}$ \\
\hline
\end{tabular}



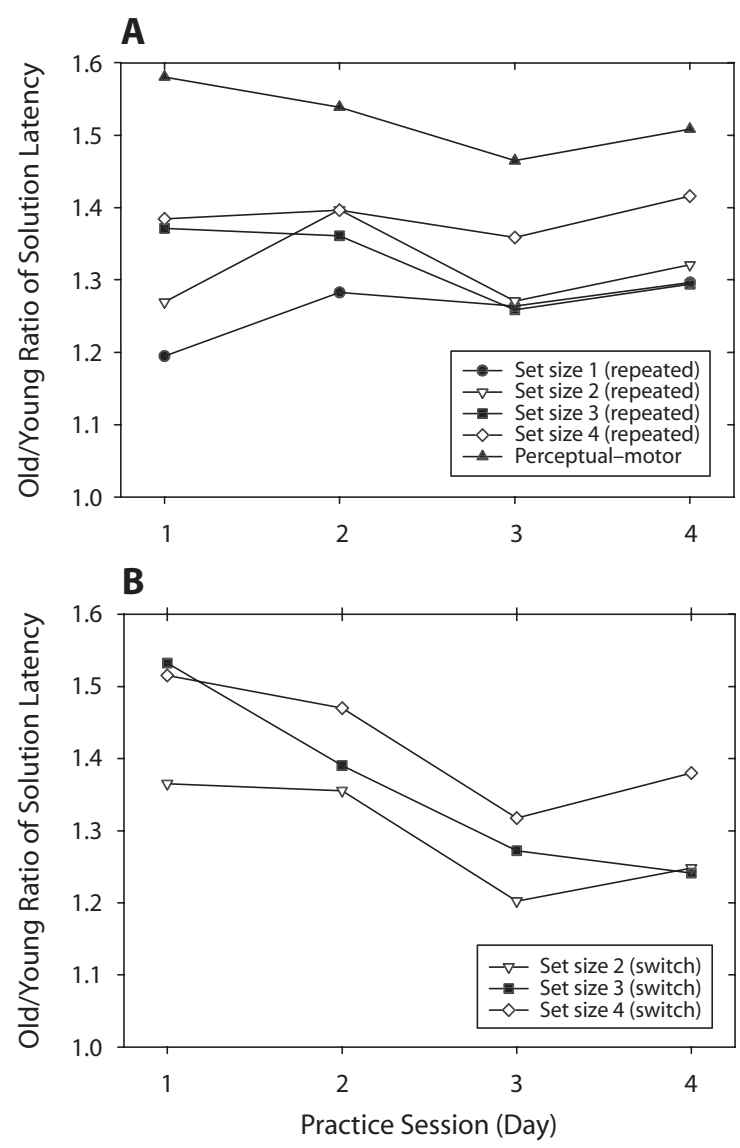

Figure 3. Ratio of older adult over young adult mean median solution latencies as a function of training session (Days 1-4) and task set size for perceptual-motor and task-repetition trials (panel A) and task-switch trials (panel B).

ing more than perceptual-motor slowing in highly trained older adults. This possibility is highly significant, because it runs counter to the typical findings of the field. A number of cognitive aging researchers (Cerella, 1990; Salthouse, 1996; Verhaeghen, Kliegl, \& Mayr, 1997) have generally observed that the magnitude of age differences increases as the processing demands - or complexity - of the task increases (for a meta-analysis, see Cerella, 1985).

We tested the simplest case - the set size 1 conditionfor the possibility that age-related differences could be explained by perceptual-motor slowing. For each participant, we subtracted the median digit copy RT from their median set size 1 RT. A one-factor ANOVA (young vs. old) on the adjusted RT data showed that the age effect had been eliminated $\left[F(1,124)=0.30, M S_{\mathrm{e}}=24,544\right.$, n.s.]. Thus, the age effect disappeared in pure number reduction, with no task switching and no input-output perceptual-motor operations. Thus, age-related differences can be attributed to perceptual-motor slowing - an outcome reported in other studies of mental arithmetic (Birren, Allen, \& Landau, 1954; Birren \& Botwinick, 1951; Salthouse \& Coon, 1994; Sliwinski, 1997).
Pushing the perceptual-motor slowing hypothesis further to examine task switching, we adjusted RTs from all set sizes in the same manner. The entire set of ANOVAs that were reported in the previous section was then repeated on the perceptual-motor adjusted RT values, and it is summarized in the two right columns of Table 2 alongside the values reported in the previous analysis on raw RTs in the two left columns. The outcomes of this new set of ANOVAs were essentially unchanged from the original outcomes, and the entire ensemble of effects due to age, set size, switch/ nonswitch status-together with their interactionsreplicated those found for the raw RTs. The degree to which age-related differences were diminished by adjusting the data for perceptual-motor speed is striking, however.

In support of the perceptual-motor slowing hypothesis, a sizeable amount of age-related differences were associated with the basic input-output processes of the digit copy task. It is surprising that such large age-related differences are attributable to lower rather than to higher levels of the cognitive hierarchy. However, we also found that older adult performance suffered in the most demanding experimental condition. A series of focused age group contrasts at each level of the set size manipulation for task-repetition trials (Table 2, bottom right) revealed age-related differences only in set size 4 of the perceptual-motor adjusted trained data. Amazingly, age effects disappeared after adjusting the data for perceptual-motor speed, since older adults had equivalent performance to that of young adults for task-repetition trials in set sizes 1,2 , and 3 . This was not the end result of practice per se, since age equivalence was also found in the adjusted Session 1 data for set sizes 1 and 2 (Table 2, bottom). And - as was discussed in the previous section using age ratios - young and older adults had equivalent practice-related improvement to performance on task-repetition trials and on the digit copy task. Clearly there is some age sensitivity to the highest levels of the set size manipulation that is not attributable to an age-related slowing of perceptual-motor speed.

In the following sections, we will explore the set size main effect further in relation to two functions-run length and lag recency. These two functions have been used to highlight different aspects of cognitive control. Lag recency describes the cost of reengaging a "passive" task that has been switched away from as a function of the number of intervening trials. On the other hand, the run length function describes performance over successive repetitions of a currently "active" task. This function has been used to describe whether cognitive control is fully committed to an "active" task or whether performance improves incrementally over successive repetitions of a task (e.g., Rogers \& Monsell, 1995).

\section{Run Length}

The repetition benefit was assessed for each task as a function of the length of the run of task-repetition trials following a task switch (see Rogers \& Monsell, 1995, Figure 5). These data are shown averaged (mean of medians) across tasks in Figure 4 for young adults (top panels) and older adults (bottom panels) for Session 1 (left panels) and trained performance (right panels). Runs of length greater 

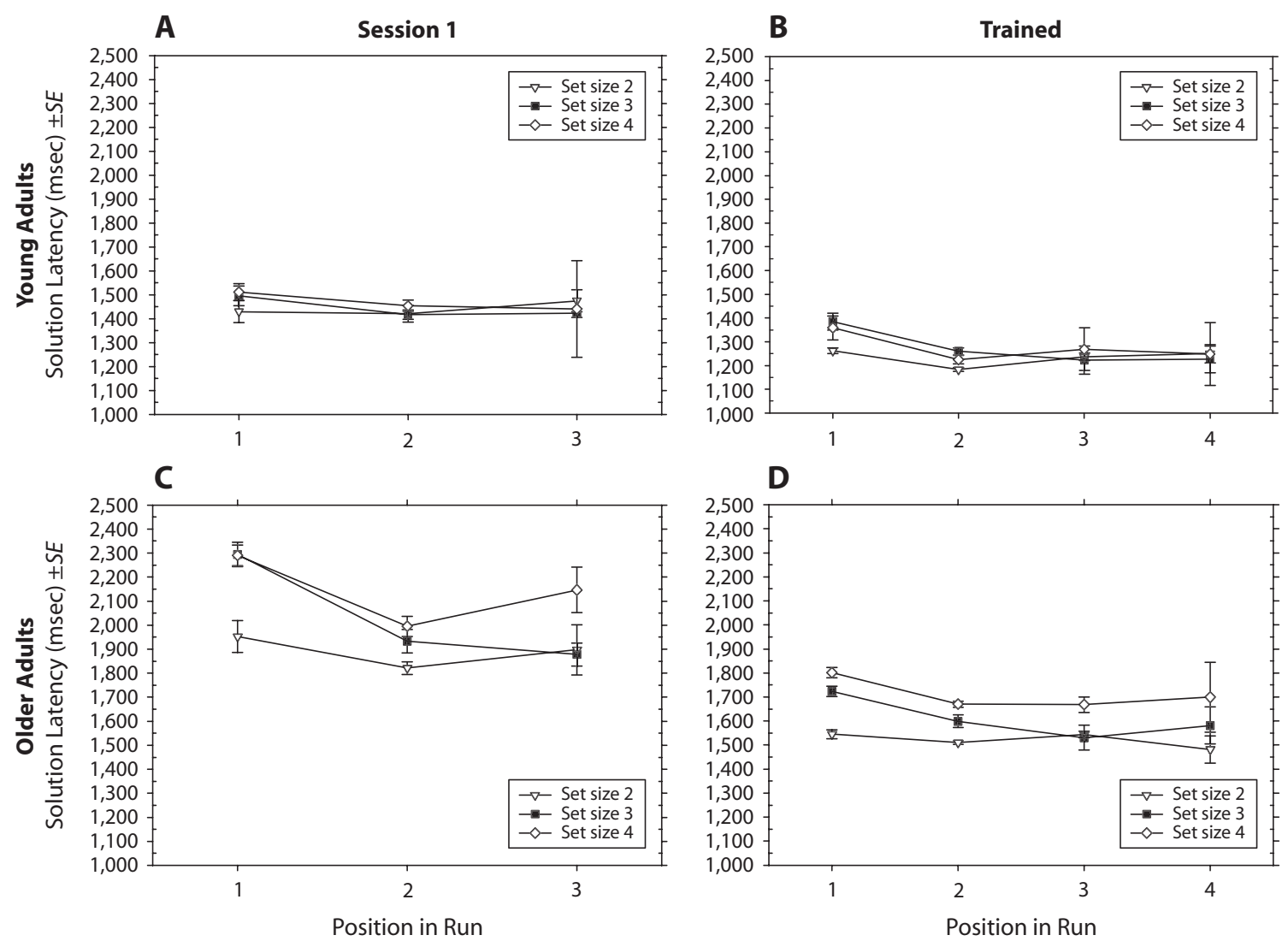

Figure 4. Young and older adult mean median solution latency as a function of run length, or the consecutive number of repeated occurrences of a given task within set size, for Session 1 and trained performance.

than three are omitted from the statistical analyses, since the corresponding cell sizes were not robust. Starting with the Session 1 data, the RTs for the young and older adults on the four tasks were analyzed in a 2 (age group) $\times 3$ (set sizes $2,3,4) \times 3$ (runs of $1,2,3$ ) ANOVA. All three main effects were significant: age $\left[F(1,1081)=251.96, M S_{\mathrm{e}}=\right.$ $78,556,693, p<.0001]$, set size $[F(2,1081)=6.36$, $\left.M S_{\mathrm{e}}=1,983,211, p<.01\right]$, and runs $[F(2,1081)=7.59$, $\left.M S_{\mathrm{e}}=2,366,354, p<.001\right]$. Two age-related interactions were significant: age $\times$ set size $[F(2,1081)=3.28$, $\left.M S_{\mathrm{e}}=1,023,900, p<.05\right]$ and age $\times$ runs $[F(2,1081)=$ 4.23, $\left.M S_{\mathrm{e}}=1,319,131, p<.05\right]$.

Continuing with the trained data, RTs for the young and older adults on the four tasks were also analyzed in a 2 (age group) $\times 3$ (set sizes $2,3,4) \times 3$ (runs of 1 , 2,3) ANOVA. All three main effects were significant: age $\left[F(1,1081)=161.31, M S_{\mathrm{e}}=34,254,497, p<.0001\right]$, set size $\left[F(2,1081)=6.21, M S_{\mathrm{e}}=1,318,126, p<.01\right]$, and runs $\left[F(2,1081)=6.04, M S_{\mathrm{e}}=1,282,420, p<.01\right]$. However, none of the interactions were significant, including those of age $\times$ set size $\left[F(2,1081)=1.87, M S_{\mathrm{e}}=396,586\right.$, n.s. $]$, and age $\times$ runs $\left[F(2,1081)=0.13, M S_{\mathrm{e}}=28,509\right.$, n.s.]. Thus, extended training eliminated specific age-related interactions with both set size and length of the run.
The run length main effect was explored in the trained data by a series of planned contrasts for runs of 1,2 , and 3 . For the young adult data, successive run positions were contrasted: position 1 versus position $2[F(1,360)=5.39$, $\left.M S_{\mathrm{e}}=1,143,829, p<.05\right]$ and position 2 versus position 3 $\left[F(1,360)=0.22, M S_{\mathrm{e}}=46,363\right.$, n.s. $]$. For the older adult data, successive run positions were also contrasted: position 1 versus position $2\left[F(1,384)=4.22, M S_{\mathrm{e}}=896,809\right.$, $p<.05]$ and lag 2 versus lag $3\left[F(1,384)=0.07, M S_{\mathrm{e}}=\right.$ 14,425 , n.s.]. The pattern of results was similar for both young and older adults; the beneficial effect of repetition was conferred equally to the second position in the run.

This result supports prior research by Rogers and Monsell (1995), who have made the run position function a centerpiece of their task set configuration theory. It was also taken up as a major challenge in Gilbert and Shallice's (2002) proactive interference theory. Rogers and Monsell (see Figure 4) argued that the task-switch cost is largely confined to the first trial in a run and that the repetition benefit quickly saturates after one task repetition (run position 2). This function was taken to reflect a "one-off process" of task-set reconfiguration at the beginning of switch trials rather than the gradual dissipation of a carryover interference effect from the previous task, as argued 

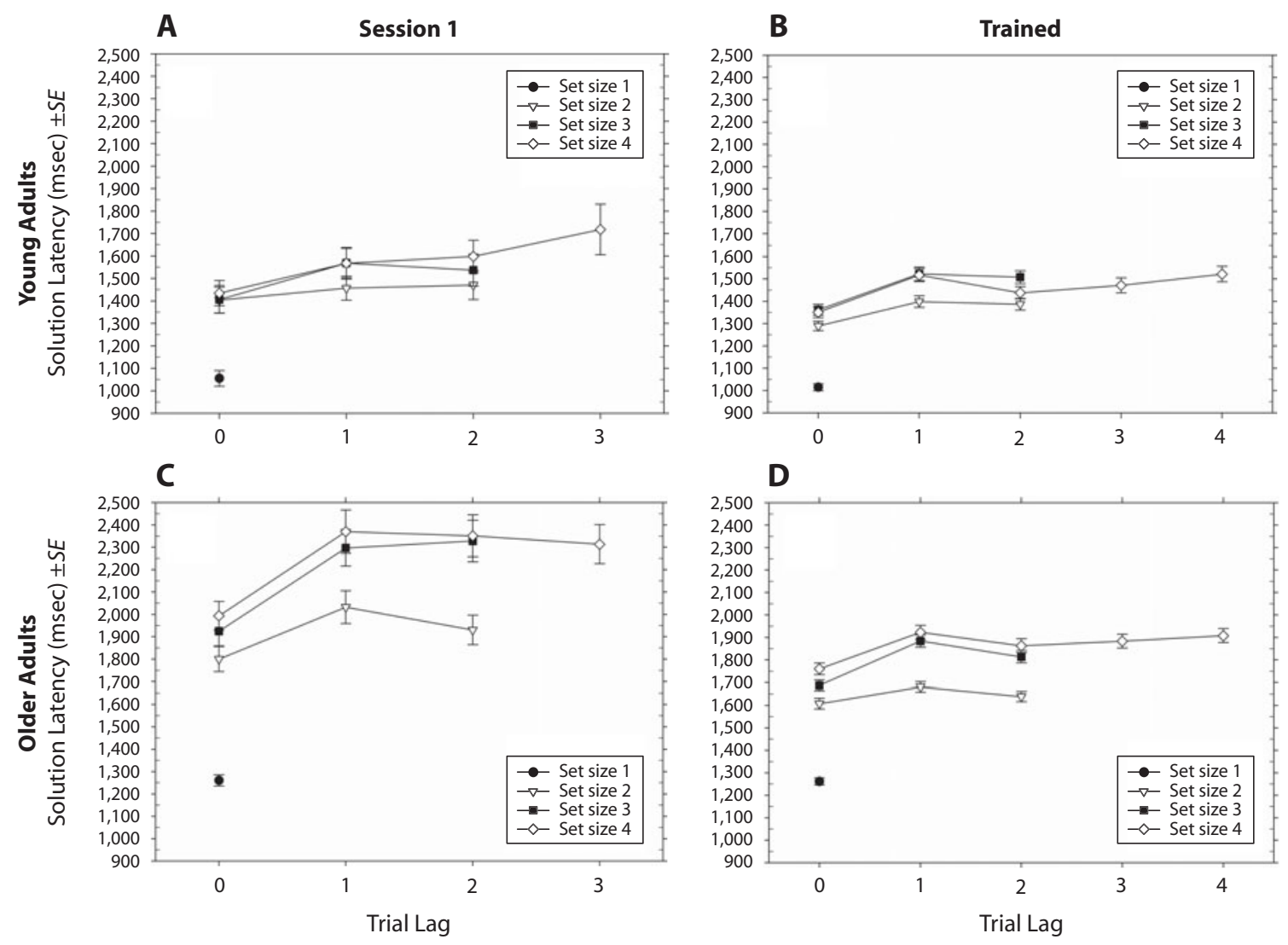

Figure 5. Young and older adult mean median solution latency as a function of trial lag, or the number of intervening trials between occurrences of a given task, and task set size for Session 1 and trained performance.

by the task set interference account (Allport et al., 1994; Allport \& Wylie, 1999, 2000; for a discussion, see Gilbert \& Shallice, 2002, pp. 300-302). After training, our data suggest that both young and older adults were equally able to completely shift focus to the active task after only one task repetition; there were no specific age effects.

\section{Lag Recency}

As a complementary analysis to the run length data, RTs were examined in terms of either the lag or the number of intervening trials between the first and second occurrence of a given task at each set size. These data are shown in Figure 5 for young adults (top panels) and older adults (bottom panels) for Session 1 (left panels) and trained performance (right panels). A lag of 0 denotes a task repetition, whereas a lag greater than 0 specifies both a task switch and the number of intervening trials before switching back to a given task. Session 1 performance was analyzed first, and RTs for the young and older adults were submitted to a 2 (age group) $\times 3$ (set sizes $2,3,4) \times 3($ lags $0,1,2)$ ANOVA. The data for lags greater than 2 were omitted from the analyses, since the corresponding cell sizes were not robust. All three main effects were significant $(p<.0001)$ : age $[F(1,1081)=$ $\left.337.22, M S_{\mathrm{e}}=106,715,662\right]$, set size $[F(2,1081)=13.49$, $\left.M S_{\mathrm{e}}=3,019,985\right]$, and lag $\left[F(2,1081)=18.11, M S_{\mathrm{e}}=\right.$ $5,731,004]$. A number of age-related interactions were significant, including age $\times$ set size $[F(2,1081)=4.55$, $\left.M S_{\mathrm{e}}=1,439,999, p<.05\right]$ and age $\times$ lag $[F(2,1081)=$ $\left.3.75, M S_{\mathrm{e}}=1,185,238, p<.05\right]$.

After training, RTs for practiced young and older adults were also analyzed in a 2 (age group) $\times 3$ (set sizes $2,3,4) \times 3($ lags $0,1,2)$ ANOVA. All three main effects were significant $(p<.0001)$ : age $[F(1,1081)=$ $\left.170.81, M S_{\mathrm{e}}=37,064,547\right]$, set size $[F(2,1081)=13.92$, $\left.M S_{\mathrm{e}}=3,019,985\right]$, and lag $\left[F(2,1081)=14.23, M S_{\mathrm{e}}=\right.$ $3,087,373]$. Only the age $\times$ set size interaction was significant $\left[F(2,1081)=2.94, M S_{\mathrm{e}}=638,516, p<.05\right]$. Thus, after extensive practice, the age $\times$ lag interaction was no longer significant $\left[F(2,1081)=0.04, M S_{\mathrm{e}}=9,126\right.$, n.s. $]$. The age $\times$ set size interaction in the lag recency function was the only significant age-related interaction evident in all aspects of trained performance.

This specific age effect demonstrates that older adults are susceptible to the mental load of maintaining and switching between multiple task sets, even after extended training. It is noteworthy that this interaction between age and task set size could not be "trained away." This result 
differs from our previous analyses of the general set size function and the run length function in which all agerelated interactions were eliminated with practice. That the age $\times$ lag interaction was eliminated with training in the lag recency function suggests that older adults do not simply have difficulty reengaging a "passive" task, but that additional costs are incurred in relation to the number of additional tasks in the set. It may be that after extensive practice, switching tasks is more or less triggered automatically by the color of the digits in young adults, whereas task switching is more effortful in older adults in relation to the number of tasks in the set. Next, we focus on the engagement and disengagement of tasks, as detailed by a series of contrasts in the trial lag function of Figure 5.

The lag main effect was explored in the trained data by a series of contrasts for lags 0,1 , and 2 . For the young adult data, successive lags were contrasted: lags 0 versus 1 $\left[F(1,360)=13.24, M S_{\mathrm{e}}=2,643,673, p<.001\right]$, and lags 1 versus $2\left[F(1,360)=0.34, M S_{\mathrm{e}}=67,258\right.$, n.s.]. For the older adult data, successive lags were also contrasted: lags 0 versus $1\left[F(1,384)=12.63, M S_{\mathrm{e}}=2,921,319, p<.001\right]$, and lags 1 versus $2\left[F(1,384)=0.87, M S_{\mathrm{e}}=201,605\right.$, n.s. $]$. The pattern of results was similar for both young and older adults; repetition improved performance for nonswitch trials or trials in immediate succession (lag 0 ). The analysis showed further that lag effects did not differ significantly between lags 1 and 2. Thus, after a task switch, it did not matter whether a task was reinstated after 1 or 2 trials; the switching penalty was of similar magnitude.

A number of researchers have found that switching back to a just-performed task after a task switch (lag 1) yields a slight increase in latencies in comparison with longer lags (lag 2) (Arbuthnott \& Frank, 2000; Mayr, 2002; Mayr \& Keele, 2000). The effect is a small one; it has been enlisted in support of the view that inhibition is necessary to counteract proactive interference arising from switching tasks. This trend is apparent in the dip that can be seen at lag 2, but it did not reach statistical significance in our present data. Moreover, the trend then reverses, and RTs rise for lags 3 and 4 . This subsequent rise after the dip suggests either a dissipation of proactive interference at longer lags or the existence of second-order effects, such as decaying task-set activation. ${ }^{3}$

\section{Empirical Summary}

By the third of five training sessions, learning curves bottomed out, and both young and older adults achieved baseline (asymptotic) performance on the number reduction tasks on measures of both latency and accuracy. The general form of the asymptotic latency function describing task selection and execution was curvilinear across task set size, with an especially large step increase from the single task baseline (set size 1) to the task-switching conditions (set size $>1$ ). This initial step increase is thought to reflect the repetition benefit afforded to the just performed task (i.e., repetition priming), which occurs continuously in the set size 1 condition, and the costly engagement of processes involved in cognitive control for the task-switching conditions (set size $>1$ ). Our results demonstrate that there are two components to cognitive control: costs associated with actively switching tasks, and costs associated with interference or maintaining a set of other tasks to be attended to.

The accessibility of all tasks - whether currently active or disengaged - was systematically affected by the set size manipulation. However, as the number of tasks to be maintained in the set increased, there were diminishing incremental costs to the time taken to perform a task. That is, task solution latency did not balloon; instead, the step increases in solution latency cost decreased in size with each additional task to be performed. Remarkably, taskswitch costs also did not increase significantly with the number of other tasks to be performed. This lack of interaction between switch cost and task set size suggests that the engagement of the processes active in shifting cognitive control are largely a one-time fixed cost, as evident by the large step increase from set size 1 to set size 2 .

Age effects in task-switching performance-evident early in practice - were effectively "practiced away" after three consecutive days of training. In addition, the remaining age-related difference in task solution latencies across set size were largely removed when the function was corrected for individual perceptual-motor speed scores. The ability of older adults to rapidly switch between tasks was shown to improve markedly with practice-much more so than it was in young adults. Other aspects of taskswitching performance - for example, task repetition and perceptual-motor speed - improved equally with practice for both young and older adults. These findings demonstrate that although training can eliminate age-related differences in task switching, perceptual motor differences are largely immutable.

\section{GENERAL DISCUSSION}

Two distinctive findings of the present study were (1) age-related differences in task-switch costs were eliminated with extended practice (see also Kramer et al., 1999) - remarkably, even when managing the execution of up to four tasks - and (2) task-switch costs were largely a one-time cost, with small diminishing incremental costs as the number of possible tasks was incremented from two to four tasks (see also Kray et al., 2002). This second finding can be understood from an intuitive and ecological perspective. In responding to the complexity of our everyday environments, we typically draw on a vast repertoire of task sets, and the penalty in task switching is mainly associated with going from one task to any other task, regardless of the number of task sets at our disposal. A cognitive system configured differently, with substantially increased switch costs as a function of the size of our task-set repertoire, would leave us unable to respond appropriately in a timely manner.

It is noteworthy that this cognitive configuration is consistent with production system postulates (Anderson \& Lebiere, 1998; Meyer \& Kieras, 1997), stating that an information-processing system is governed by a library of production rules that specify-for a given stimulus configuration - the requisite processing procedure. A 
production rule is essentially a condition-action pair-or, more formally, an if . . . then statement - so that if the conditional clause is satisfied, then the system produces the corresponding action. The course of information processing can be characterized by the sequence of production rule firings. An explicit assumption of this system is that all of the productions in the library are accessed in parallel in an attempt to find a matching production. This assumption is consistent with our results, since increasing the size of the production rule library did not substantially alter the behavior of the system. Next, we discuss our main findings in terms of task switching and availability, task-set activation dynamics, and the elimination of age-related differences in task switching with extended practice.

\section{The Availability of Tasks During Task Switching}

Two different types of task complexity were imposed on the cognitive system: (1) the imposition of task switching, and (2) an increase in the number of task sets to be actively maintained. These two complexity costs were shown to be independent of one another. The analysis of trial lag recency demonstrated that only one task - the currently active one - was actively maintained in a heightened state of accessibility. All recently disengaged tasks were equally accessible. The execution time decreased markedly for a task if it had just been performed - as would be expected from the repetition benefit (i.e., repetition priming). This result is consistent with a number of accounts of task switching, including computational accounts based on the dynamics of task activation and decay. Furthermore, aside from the repetition benefit given to the currently active task, the accessibility of all disengaged tasks was shown to be dependent on the total number of tasks in the set. Before turning our attention to this second result, we first discuss a framework for understanding the repetition benefit afforded to the currently active task.

\section{Task-Set Activation Dynamics}

Adopting the notion of activation dynamics, when a given task set is performed, it receives a boost in activation and is more accessible (i.e., has a higher activation) than other task sets. The task set is subsequently subjected to a time-based decay of activation. If a task set reoccurs before decaying to its initial base level of activation, then that task set is more accessible, since less activation is required for its reactivation above a given threshold, which is the basis for the repetition benefit (e.g., McElree, 1998, 2001). In our data, there was no benefit to reinstating a task after it had been disengaged or switched away from. Presumably, the temporal delay between the disengagement and reinstatement of a given task was long enough so that task activation had already decayed to its base level of activation. At a lag of 1 trial, the elapsed time was $3.4 \mathrm{sec}$ (two interstimulus intervals; ISI) - plus the response latency of the intervening trial-for a total elapsed time of $\sim 5$ or $6 \mathrm{sec}$. The results of Sohn and Anderson (2001), demonstrated that the repetition benefit to a currently active task disappears after $5 \mathrm{sec}$. In our data, this time period corresponds to a lag of 1 trial. In other words, only task repetitions (lag of 0 ) benefited from residual activa- tion, which disappears after 1 trial. Our results then are amenable to a time-based decay account of the contrast between the lag of 0 and 1 , as well as between lags $>0$. For future research, curvilinear trial-lag recency curves should be obtained if our ISI is foreshortened.

This mechanism for determining accessibility is regularly employed in computational architectures - such as production systems (e.g., ACT-R; Anderson \& Lebiere, 1998) - and it involves granting a temporary boost in activation that is then subject to rapid time-based decay. In the ACT-R model, privileged access is determined by the temporal lag between the current and prior presentation of a memory element. The production system architecture proposes that this heightened state of accessibility decays logarithmically over time. Along these lines, Altmann (2002) advanced a model that accounts for decay of activation, in which cognitive control arises from activation-based memory processes. However, decay of activation is insufficient by itself to account for the global effects resulting from our set size manipulation. That is, if privileged access is determined by the temporal decay of residual activation of a task, then this effect should be purely task dependent and independent of the number of other tasks in the set. Our task-specific lag recency analysis demonstrated that this was clearly not the case, since task latencies at all temporal trial intervals were systematically prolonged by the set size manipulation. From our run position analysis, even the solution latencies for task-repetition trials were delayed with increasing task set size. It is therefore necessary to posit a secondary global mechanism that prolongs all task latencies as a function of the set size manipulation.

\section{Cognitive Control and Multiple Tasks}

All response latencies-whether task-switch or taskrepetition trials-were systematically attenuated or less accessible with increasing task set size. The set size manipulation attenuated repeated tasks as well as recently disengaged tasks, and these results point to a global determinant of task selection and execution latencies. One possibility is that tasks demand general resources from the processing system. This resource dilution account suggests that a fixed amount of processing resources is allocated to maintain one or more task sets in a state of heightened availability. A key difference between this source activation account (see also Daily, Lovett, \& Reder, 2001; Lovett, Reder, \& Lebiere, 1999) and other accounts proposed in the task-switching literature (failure to engage, De Jong, 2000; task-set reconfiguration, Rogers \& Monsell, 1995) is that preparedness or additional source activation is distributed to all possible tasks. This mechanism of spreading activation to all constituents has been shown to yield curvilinear functions with increasing $n$ (see Lovett et al., 1999), which was the form of our task set size function. Both of the other accounts - failure to engage and taskset reconfiguration - are largely based on switch tasks in which advanced preparation was possible by means of a task cue, and they therefore postulate an all-or-none discrete process of preparation. The resource dilution account could accommodate these accounts by shifting resources in an all-or-none fashion in predictable task switching. 
In contrast, in unpredictable task switching, the cognitive system maintains all of the relevant tasks - given resource limitations - in a state of heightened accessibility (see Los, 1999; Monsell et al., 2003). Yet, it is unclear how resource dilution could account for some findings in the task-switching literature that have been explained by other mechanisms, such as task set inertia.

A second possibility is that the observed systematic increases in response latency with task set size are due to a corresponding increase in interference among the tasks. This account has been advanced by a number of researchers, as specified by the task set inertia hypothesis (Allport et al., 1994; Allport \& Wylie, 1999, 2000; Arbuthnott \& Frank, 2000; Mayr, 2002; Mayr \& Keele, 2000; Meuter \& Allport, 1999; Nieuwenhuis \& Monsell, 2002). These researchers have argued that task-switch costs are best described as a form of proactive interference, whereby the configuration of a previous task contributes persisting interference, or task set inertia. Some of the strongest evidence for task set inertia is that it can account for asymmetries in task-switch costs and the counterintuitive finding that switch costs are larger when switching to a routine task (e.g., word naming) than to a less familiar (e.g., color naming) task (Allport et al., 1994; see also Yeung $\&$ Monsell, 2003). Allport et al. reasoned that strong topdown control was applied in performing the weaker colornaming task, and that overcoming this bias in control settings resulted in larger switch costs when switching to the routine word-naming task. Our tasks were not asymmetrical, since extensive pilot testing was used to select a set of four tasks of equivalent computational complexity. However, it is possible that our task set size effects were due to compounded interference arising from multiple tasks that persisted throughout the block.

A number of other findings have also been enlisted in support of task set inertia. For example, Mayr and Keele (2000) used a lag recency function to demonstrate backward inhibition; it was more difficult to switch back to a task that had just been switched away from (lag of 1) than to switch back to a task that had not been recently performed. Although an inflection is evident in our lag recency data, it did not reach statistical significance. A critical difference between our experimental design and those in previous studies is the degree to which retrieving particular response mappings contributes to the task-switch cost (see Mayr, 2001). For instance, Schuch and Koch (2003) demonstrated that backward inhibition depends on response-selection competition, which is when different categorical responses (e.g., odd-even vs. high-low) need to be mapped on the same set of keys. Our experiment differed in that it did not have specific response maps associated with each task set, since participants simply keyed in the numeric solution. Thus, our findings of weak backward inhibition supports previous research showing that the reconfiguration of response mappings crucially contribute to backward inhibition. ${ }^{4}$

\section{Task Expectancy and Block-Level Cuing}

Our experimental conditions - unpredictable and instantaneous task-cuing with no necessary reconfiguration of response mappings - allowed us to focus on the effects of task set size on task-switching performance. A key aspect of our design - preparedness - was maintained at the level of the block, since participants were told in advance which tasks constituted the upcoming block (e.g., addition \& smallest +1 tasks). This differs from previous studies that focus preparedness on a specific task with either advanced cuing at the level of the trial (Sohn \& Anderson, 2001; Rogers \& Monsell, 1995) or that require participants to keep track of when to switch in a run of trials (e.g., Kramer et al., 1999). It is likely that a sizeable portion of the switch cost involved processing the instantaneous color cue in order to enable the appropriate task set. An important area for future research is the degree to which set size effects can be reduced with advanced preparation at the trial level. This manipulation would address how much of the set size effects involve endogenous preparatory control processes, such as processing up to four task cues.

With instantaneous task cues, it is possible that participants shift expectations for a task switch or a task repetition during the ISI and prepare accordingly. After successive repetitions of a task, participants expect or anticipate a task repetition. In this account, it is assumed that participants anticipate shifting probabilities and maintain any given task in a heightened level of preparedness. However, the conditional probabilities of a task switch or a task repetition based on both run position and trial lag did not support this expectancy account. First, the conditional probability of repeating a task based on run length (Figure 4 ) is position $1(32 \%)$, position $2(13 \%)$, position $3(18 \%)$, and position $4(13 \%)$. Such low probabilities of a task repetition conditioned on run position go against an expectancy account of the observed performance gains with increased run length. Second, the conditional probability of switching back to a previously disengaged task as a function of trial lag (Figure 5) is lag 1 (13\%), lag 2 (16\%), lag $3(23 \%)$, and lag $4(29 \%)$. These increases in conditional probability cannot explain the rise in response latencies in the tail of the trial lag function; successful anticipation of a task switch would decrease response latencies. These findings suggest that tasks are not biased in anticipation of either a task repetition or a task switch. Rather, our set size results suggest that in an unpredictable environment, preparedness was maintained for all tasks and not in anticipation of a possible task repetition or task switch.

\section{Training and Executive Control in Old Age}

A startling finding in line with prior research (Kramer et al., 1999) was that age-related differences in taskswitching performance disappeared by the third training session. The age-related comparison of asymptotic levels of performance controlled for age-related differences in the rate of learning. Older adults required an extra session (Day 3) to achieve asymptotic performance in comparison with young adults (Day 2). Older adult task-switching performance improved markedly over three training sessions; age-related differences in task-switching performance were eliminated. This positive result supports the use of interventions to effectively train older adults to rapidly shift between tasks. 
An important new finding was that age-related differences did not substantially increase with task set sizethat is, with the number of tasks to be executed. After extensive training, older adults were just as able to switch between multiple tasks as were young adults. Age-related differences were largely manifest at low levels in the cognitive hierarchy, in perceptual motor speed. In fact, after adjusting the trained data for individual differences in perceptual motor speed, some age differences disappeared altogether, since older adults were just as fast as young adults in solving repeated tasks at set sizes 1,2 , and 3 (not 4).

In contrast with task switching, perceptual-motor speed was an immutable age-related difference that did not benefit from training. After two sessions of training, the age-related slowing factor in the perceptual motor speed task was 1.48, which conforms to estimates in the aging literature (e.g., Cerella, 1985). Our findings also concur with studies showing that arithmetic calculation is generally unimpaired by aging, perhaps because of practical arithmetic aptitude associated with older cohorts (Geary et al., 1993). A number of cognitive aging researchers have found that age-related differences are greater at the intercept or at lower levels of complexity in arithmetic tasks, and they have isolated such effects as being due to disproportional writing speed (Birren et al., 1954; Birren \& Botwinick, 1951), physical identity judgments (Salthouse \& Coon, 1994), and enumeration initiation speed (Sliwinski, 1997). This runs counter to other domains in cognitive aging research in which finding an age $\times$ complexity interaction is the norm. An important question for future research is whether age effects can be eliminated with training in other domains as well.

There was one specific age effect that did not disappear with practice. When having to switch back to a previously performed task, our analysis of trial lag demonstrated that older adults did incur additional switch costs in relation to the set size manipulation. This result suggests that in the young adults, the task sets were cued relatively automatically by the color of the digits, whereas more deliberate effort was required by older adults to maintain the correspondence between color cue and task set.

\section{CONCLUSION}

In this article, a training intervention eliminated agerelated difficulties in managing multiple tasks. Furthermore, task set size was found to be a global determinant of solution latencies, since it affected all aspects of performance. By considering task switching beyond two tasks, we found evidence for a cognitive control system that is not overwhelmed by task set size load manipulations. Task-switch costs were found to adhere to a step function, with a large fixed cost in going from a single task to a multitask environment. It remains to be examined whether there is a limit - beyond four tasks - to trained multitasking performance after which performance breaks down, or whether, in line with the postulates of production systems, there is no effective limit in mental capacity to the number of learned productions.

\section{AUTHOR NOTE}

This research was made possible by Grant AG11451 from the National Institute of Aging to J.C. and W.J.H., and by fellowship support to N.G.B. by the Dr. Eric F. Gardner Memorial Foundation. The research reported in this article was conducted as part of N.G.B.'s doctoral dissertation submitted to Syracuse University. We thank members of the dissertation committee, who - in addition to J.C. and W.J.H. - were Marc Howard, Martin Sliwinski, and Paul Verhaeghen. We also thank our reviewers, Eric Ruthruff and Ulrich Mayr. Correspondence concerning this article should be addressed to N. G. Buchler, Center for Cognitive Neuroscience, Duke University, B254 Levine Science Research Center, Durham, NC 27708-0999 (e-mail: norbou.buchler@duke.edu).

\section{REFERENCES}

Allport, D. A., Styles, E. A., \& Hsieh, S. (1994). Shifting intentional set: Exploring the dynamic control of tasks. In C. Umiltà \& M. Moscovitch (Eds.), Attention and performance $X V$ : Conscious and nonconscious information processing (pp. 421-452). Cambridge, MA: MIT Press.

Allport, D. A., \& Wylie, G. R. (1999). Task-switching: Positive and negative priming of task-set. In G. W. Humphreys, J. Duncan, \& A. M. Treisman (Eds.), Attention, space, and action: Studies in cognitive neuroscience (pp. 273-296). Oxford: Oxford University Press.

Allport, [D.] A., \& Wylie, G. [R.] (2000). Task switching, stimulusresponse bindings, and negative priming. In S. Monsell \& J. Driver (Eds.), Control of cognitive processes: Attention and performance XVIII (pp. 35-70). Cambridge, MA: MIT Press.

Altmann, E. M. (2002). Functional decay of memory for tasks. Psychological Research, 66, 287-297.

Anderson, J. R., \& Lebiere, C. (1998). The atomic components of thought. Mahwah, NJ: Erlbaum.

Arbuthnott, K., \& Frank, J. (2000). Executive control in set switching: Residual switch cost and task-set inhibition. Canadian Journal of Experimental Psychology, 54, 33-41.

Birren, J. E., Allen, W. R., \& Landau, H. G. (1954). The relation of problem length in simple addition to time required, probability of success, and age. Journal of Gerontology, 9, 150-161.

BirRen, J. E., \& BotwinICK, J. (1951). Rate of addition as a function of difficulty and age. Psychometrika, 16, 219-232.

Cepeda, N. J., Kramer, A. F., \& GonZales de Sather, J. C. M. (2001). Changes in executive control across the life-span: Examination of taskswitching performance. Developmental Psychology, 37, 715-730.

Cerella, J. (1985). Information processing rates in the elderly. Psychological Bulletin, 98, 67-83.

Cerella, J. (1990). Aging and information-processing rate. In J. E. Birren \& K. W. Schaie (Eds.), Handbook of the psychology of aging (3rd ed., pp. 201-221). San Diego: Academic Press.

Daily, L. Z., Lovett, M. C., \& Reder, L. M. (2001). Modeling individual differences in working memory performance: A source activation account. Cognitive Science, 25, 315-353.

De Jong, R. (2000). An intention-activation account of residual switch costs. In S. Monsell \& J. Driver (Eds.), Control of cognitive processes: Attention and performance XVIII (pp. 357-376). Cambridge, MA: MIT Press.

FAGOT, C. (1994). Chronometric investigations of task switching. Unpublished doctoral dissertation, University of California, San Diego.

Geary, D. C., Frensch, P. A., \& Wiley, J. G. (1993). Simple and complex mental subtraction: Strategy choice and speed-of-processing differences in younger and older adults. Psychology \& Aging, 8, 242-256.

Gilbert, S. J., \& Shallice, T. (2002). Task switching: A PDP model. Cognitive Psychology, 44, 297-337.

Hahn, S., Andersen, G. J., \& Kramer, A. F. (2004). Age influences on multi-dimensional set switching. Aging, Neuropsychology, \& Cognition, 11, 25-36.

Jersild, A. T. (1927). Mental set and shift. Archives of Psychology, 14(Whole No. 89), 1-81.

Kieras, D. E., Meyer, D. E., Ballas, J. A., \& Lauber, E. (2000). Modern computational perspectives on executive mental processes and cognitive control: Where to from here? In S. Monsell \& J. Driver (Eds.), Control of cognitive processes: Attention and performance XVIII (pp. 681-712). Cambridge, MA: MIT Press. 
Koch, I., Prinz, W., \& Allport, A. (2005). Involuntary retrieval in alphabet-arithmetic tasks: Task-mixing and task-switching costs. Psychological Research, 69, 252-261.

Kramer, A. F., HAHn, S., \& Gopher, D. (1999). Task coordination and aging: Explorations of executive control processes in the task switching paradigm. Acta Psychologica, 101, 339-378.

Kray, J., Li, K. Z. H., \& Lindenberger, U. (2002). Age-specific changes in task-switching components: The role of task uncertainty. Brain \& Cognition, 49, 363-381.

Kray, J., \& Lindenberger, U. (2000). Adult age differences in task switching. Psychology \& Aging, 15, 126-147.

Los, S. A. (1999). Identifying stimuli of different perceptual categories in mixed blocks of trials: Evidence for cost in switching between computational processes. Journal of Experimental Psychology: Human Perception \& Performance, 25, 3-23.

Lovetr, M. C., ReDER, L. M., \& LeBIERE, C. (1999). Modeling working memory in a unified architecture: An ACT-R perspective. In A. Miyake \& P. Shah (Eds.), Models of working memory (pp. 135-182). Cambridge: Cambridge University Press.

MaYr, U. (2001). Age differences in the selection of mental sets: The role of inhibition, stimulus ambiguity, and response-set overlap. Psychology \& Aging, 16, 96-109.

MaYr, U. (2002). Inhibition of action rules. Psychonomic Bulletin \& Review, 9, 93-99.

Mayr, U., \& Keele, S. W. (2000). Changing internal constraints on action: The role of backward inhibition. Journal of Experimental Psychology: General, 129, 4-26.

Mayr, U., \& Kliegl, R. (2000). Task-set switching and long-term memory retrieval. Journal of Experimental Psychology: Learning, Memory, \& Cognition, 26, 1124-1140.

McElree, B. (1998). Attended and non-attended states in working memory: Accessing categorized structures. Journal of Memory \& Language, 38, 225-252.

McElreE, B. (2001). Working memory and focal attention. Journal of Experimental Psychology: Learning, Memory, \& Cognition, 27, 817-835.

MeIran, N. (2000). Reconfiguration of stimulus task sets and response task sets during task switching. In S. Monsell \& J. Driver (Eds.), Control of cognitive processes: Attention and performance XVIII (pp. 377-399). Cambridge, MA: MIT Press.

Meiran, N., \& Gotler, A. (2001). Modelling cognitive control in task switching and ageing. European Journal of Cognitive Psychology, 13, 165-186.

Meuter, R. F. I., \& Allport, A. (1999). Bilingual language switching in naming: Asymmetrical costs of language selection. Journal of Memory \& Language, 40, 25-40.

Meyer, D. E., \& Kieras, D. E. (1997). A computational theory of executive cognitive processes and multiple-task performance: I. Basic mechanisms. Psychological Review, 104, 3-65.

Monsell, S. (2003). Task switching. Trends in Cognitive Sciences, 7 , 134-140.

Monsell, S., Sumner, P., \& Waters, H. (2003). Task-set reconfiguration with predictable and unpredictable task switches. Memory \& Cognition, 31, 327-342.

Monsell, S., Yeung, N., \& Azuma, R. (2000). Reconfiguration of task-set: Is it easier to switch to the weaker task? Psychological Research, 63, 250-264.

National Research Council (1990). Reports of the Committee on Vision, 1947-1990 (J. S. Albanes, Ed.). Washington, DC: National Academy Press.

Newell, A., \& Rosenbloom, P. (1981). Mechanisms of skill acquisition and the law of practice. In J. R. Anderson (Ed.), Cognitive skills and their acquisition (pp. 1-56). Hillsdale, NJ: Erlbaum.

Nieuwenhuis, S., \& Monsell, S. (2002). Residual costs in task switching: Testing the failure-to-engage hypothesis. Psychonomic Bulletin \& Review, 9, 86-92.
PASHLER, H. (2000). Task switching and multitask performance (tutorial). In S. Monsell \& J. Driver (Eds.), Control of cognitive processes: Attention and performance XVIII (pp. 277-307). Cambridge, MA: MIT Press.

Rogers, R. D., \& Monsell, S. (1995). Costs of a predictable switch between simple cognitive tasks. Journal of Experimental Psychology: General, 124, 207-231.

Rubinstein, J. S., Meyer, D. E., \& Evans, J. E. (2001). Executive control of cognitive processes in task switching. Journal of Experimental Psychology: Human Perception \& Performance, 27, 763-797.

Ruthruff, E., Remington, R. W., \& Johnston, J. C. (2001). Switching between simple cognitive tasks: The interaction of top-down and bottom-up factors. Journal of Experimental Psychology: Human Perception \& Performance, 27, 1404-1419.

Salthouse, T. A. (1996). The processing-speed theory of adult age differences in cognition. Psychological Review, 103, 403-428.

Salthouse, T. A., \& Coon, V. E. (1994). Interpretation of differential deficits: The case of aging and mental arithmetic. Journal of Experimental Psychology: Learning, Memory, \& Cognition, 20, 1172-1182.

ScHuch, S., \& KocH, I. (2003). The role of response selection for inhibition of task sets in task shifting. Journal of Experimental Psychology: Human Perception \& Performance, 29, 92-105.

SLIWINSKI, M. (1997). Aging and counting speed: Evidence for processspecific slowing. Psychology \& Aging, 12, 38-49.

SoHn, M.-H., \& Anderson, J. R. (2001). Task preparation and task repetition: Two-component model of task switching. Journal of Experimental Psychology: General, 130, 764-778.

Verhaeghen, P., \& Cerella, J. (2002). Aging, executive control, and attention: A review of meta-analyses. Neuroscience \& Biobehavioral Reviews, 26, 849-857.

Verhaeghen, P., Kliegl, R., \& Mayr, U. (1997). Sequential and coordinative complexity in time-accuracy functions for mental arithmetic. Psychology \& Aging, 12, 555-564.

WeChSLER, D. (1981). The psychometric tradition: Developing the Wechsler Adult Intelligence Scale. Contemporary Educational Psychology, 6, 82-85.

Wecker, N. S., Kramer, J. H., Hallam, B. J., \& Delis, D. C. (2005). Mental flexibility: Age effects on switching. Neuropsychology, 19, 345-352.

WEST, R. L. (1996). An application of prefrontal cortex function theory to cognitive aging. Psychological Bulletin, 120, 272-292.

Wylie, G., \& AllPORT, A. (2000). Task switching and the measurement of "switch costs." Psychological Research, 63, 212-233.

YeUnG, N., \& MonsELL, S. (2003). The effects of recent practice on task switching. Journal of Experimental Psychology: Human Perception \& Performance, 29, 919-936.

\section{NOTES}

1. The schemas for set size 4 were arbitrarily selected from a large set of possibilities that satisfied the constraints of maintaining a switch probability of $66 \%$, equating task frequency, and balancing the switches to and from different tasks.

2. Contextual independence of tasks. RTs for a given task were not affected by the identity of the previously presented task with which it was paired. For example, in blocks with two tasks (set size 2), the RTs for addition were paired with subtraction in one context, with largest -1 in a second context, and with smallest +1 in a third context. Addition times did not vary across three contexts (addition vs. subtraction, addition vs. smallest +1 , and addition vs. largest -1 ). Because RTs for each task were independent of context, this allowed us to consider the effects of set size by collapsing across contexts.

3. We thank Ulrich Mayr for pointing this out.

4. We thank one of our reviewers for pointing this out.

(Manuscript received March 13, 2006; revision accepted for publication November 4,2007 .) 